\title{
O APERFEIÇOAMENTO DAS ESTIMATIVAS DAS EMISSÕES VEICULARES NO ESTADO DE SÃO PAULO, NO PERÍODO DE 2008 A 2013
}

\author{
Cristiane Dias ${ }^{1}$; Marcelo Pereira Bales ${ }^{1}$ e Silmara Regina da Silva ${ }^{1}$ \\ ${ }^{1}$ CETESB (Companhia Ambiental do Estado de São Paulo) \\ E-mails: cdias@sp.gov.br, mbales@sp.gov.br, silmsilva@sp.gov.br
}

\section{RESUMO}

De modo geral, o cálculo de emissões veiculares envolve a intensidade de uso ou quilometragem anual percorrida pelo veículo, os fatores de emissão por categoria/combustível e poluente e a frota circulante da área de interesse. Para a determinação da intensidade de uso ajustada, deve-se levar em consideração o consumo aparente de combustível no Estado de São Paulo, uma vez que a intensidade de uso de referência deve ser ajustada ao consumo de Gasolina C, Etanol Hidratado e Óleo Diesel. Os fatores de emissão por categoria/combustível e poluente são provenientes dos RVEPs (Relatório de Valores de Emissão de Produção) enviados semestralmente à CETESB (Companhia Ambiental do Estado de São Paulo). Estes valores são resultantes da média ponderada de ensaios de emissões dos modelos de veículos mais vendidos, para o acompanhamento do PROCONVE/PROMOT. Existem incertezas envolvidas na determinação de emissões veiculares, tais como: a deterioração dos fatores de emissão, os limites da área onde o combustível foi gasto e a intensidade de uso de referência dos veículos. Com relação a esta última variável, a CETESB publicou em 2014 as "Curvas de intensidade de uso por tipo de veículo automotor da frota da cidade de São Paulo" para o aperfeiçoamento das suas estimativas do inventário de emissões publicadas anualmente. $\mathrm{O}$ objetivo deste trabalho é apresentar e discutir as estimativas de emissões veiculares para o Estado de São Paulo, utilizando as novas curvas de intensidade de uso de referência por idade do veículo publicadas.

\section{INTRODUÇÃO}

Anualmente a CETESB (Companhia Ambiental do Estado de São Paulo) publica o Relatório "Emissões Veiculares no Estado de São Paulo" de acordo a metodologia adotada no 1‥ Inventário Nacional de Emissões Atmosféricas por Veículos Automotores Rodoviários (MMA, 2011) [1]; apresentando as estimativas de emissões de poluentes atmosféricos e de alguns Gases de Efeito Estufa (GEE).

De modo geral, a equação 1 é a utilizada para o cálculo das emissões de escapamento de uma frota circulante, por poluente e ano modelo de veículo. 
Onde:

$$
\mathrm{E}=\mathrm{Fr} \times \mathrm{lu} \times \mathrm{Fe} \quad \text { (equação 1) }
$$

E - taxa anual de emissão do poluente (g/ano);

$\mathrm{Fr}$ - frota circulante de veículos, considerando o ano de interesse;

lu - intensidade de uso ou quilometragem anual percorrida pelo veículo ( $\mathrm{km} / \mathrm{ano})$; e

$\mathrm{Fe}$ - fator de emissão do poluente considerado, em $\mathrm{g} / \mathrm{km}$.

Os valores de vendas anuais de veículos novos, leves e pesados, foram fornecidos pela ANFAVEA [2] (Associação Nacional dos Fabricantes de Veículos Automotores) para o Estado de São Paulo e a ABRACICLO [3] (Associação Brasileira dos Fabricantes de Motocicletas, Ciclomotores, Motonetas, Bicicletas e Similares) disponibilizou os valores correspondentes às motocicletas. Para a obtenção da frota circulante, são usadas as curvas de sucateamento fornecidas por estudos do Ministério de Ciência e Tecnologia em 2006 [4], para as categorias de veículos consideradas: automóveis, comerciais leves ciclos Otto e Diesel, motocicletas, ônibus e caminhões.

Os fatores de emissão por categoria/combustível e poluente são provenientes dos RVEPs (Relatório de Valores de Emissão de Produção) e provém da média ponderada de ensaios de emissões dos modelos de veículos mais vendidos, para o acompanhamento do PROCONVE/PROMOT. Estes relatórios são enviados semestralmente à CETESB.

A CETESB publicou em 2014 as "Curvas de intensidade de uso por tipo de veículo automotor da frota da cidade de São Paulo" [5] para o aperfeiçoamento das suas estimativas do inventário de emissões publicadas anualmente. Foram empregadas estimativas de intensidade de uso de referência ou quilometragem anual percorrida por categoria mais próximas da realidade, variando em função da idade do veículo. A partir dos valores de intensidade de uso de referência e do volume de combustíveis consumidos no Estado de São Paulo e nas Regiões Metropolitanas, foi realizado o ajuste da intensidade de uso ou da quilometragem anual percorrida.

A intensidade de uso de referência representa a quilometragem ou a distância percorrida por ano e por tipo de veículo. Esta variável apresenta uma grande incerteza, em uma frota diversificada, onde existem veículos leves e pesados, além de motocicletas, e cada categoria com um perfil próprio de utilização. Desta forma, a variável intensidade de uso de referência precisa ser ajustada em função do consumo de combustíveis observado no Estado ou região de interesse.

Em 2012 a CETESB demandou à Secretaria do Verde e do Meio Ambiente da Prefeitura de São Paulo uma série de informações obtidas no programa de inspeção ambiental do município. Entre elas, as leituras do hodômetros dos veículos inspecionados. A partir desse banco de dados, foram feitas análises estatísticas que permitem compor as novas curvas de intensidade de uso empregadas nos cálculos das emissões veiculares obtidas neste trabalho.

\section{INFORMAÇÕES GERAIS}


Os poluentes inventariados foram o monóxido de carbono (CO), os hidrocarbonetos não-metano (NMHC), incluindo as emissões evaporativas, os óxidos de nitrogênio $\left(\mathrm{NO}_{\mathrm{x}}\right)$, o material particulado (MP), o dióxido de enxofre $\left(\mathrm{SO}_{2}\right)$ e os aldeídos $(\mathrm{RCHO})$. Foi estimada a emissão de dióxido de carbono equivalente, $\mathrm{CO}_{2 e q}$, que equipara 0 potencial de aquecimento global dos Gases de Efeito Estufa $\left(\mathrm{CO}_{2}\right.$, óxido nitroso e metano) pelo conceito do potencial de aquecimento global (GWP). Não foram consideradas as emissões de $\mathrm{CO}_{2}$ oriundas dos combustíveis renováveis, o etanol hidratado, etanol anidro e biodiesel, de acordo com a metodologia de contabilização de GEE adotada na Política Estadual de Mudanças Climáticas do Estado, que segue a recomendação do IPCC(Painel Intergovernamental de Mudanças Climáticas) [6].

As emissões veiculares da maioria dos poluentes foram estimadas utilizando a abordagem "bottom-up", na qual se considera a distância anual percorrida pelo veículo e dados específicos para o cálculo das emissões. Com exceção do $\mathrm{CO}_{2}$ e do $\mathrm{SO}_{2}$, para todas as categorias, e $\mathrm{CH}_{4}$ e $\mathrm{N}_{2} \mathrm{O}$, para o ciclo Diesel, onde foi empregada a abordagem "top-down", devido à ausência de fatores de emissão específicos.

Este trabalho tem o objetivo de apresentar os resultados das estimativas de emissões de poluentes e alguns gases de efeito estufa, de origem veicular, utilizando os novos valores de intensidade de uso de referência ou quilometragem anual de referência publicados pela CETESB [5].

\section{FROTA CIRCULANTE}

A frota circulante do Estado de São Paulo para o período de 2008 a 2013, é apresentada na figura 1. O número de automóveis do ciclo Otto é superior ao número de veículos do ciclo Diesel e de motocicletas. O crescimento da frota de veículos do ciclo Otto foi de 30\% de 2008 a 2013, e as frotas circulantes do ciclo Diesel e de motocicletas apresentaram um aumento similar de $29 \%$ para cada categoria.

Figura 1. Estimativas da frota circulante no Estado de São Paulo, de 2008 a 2013

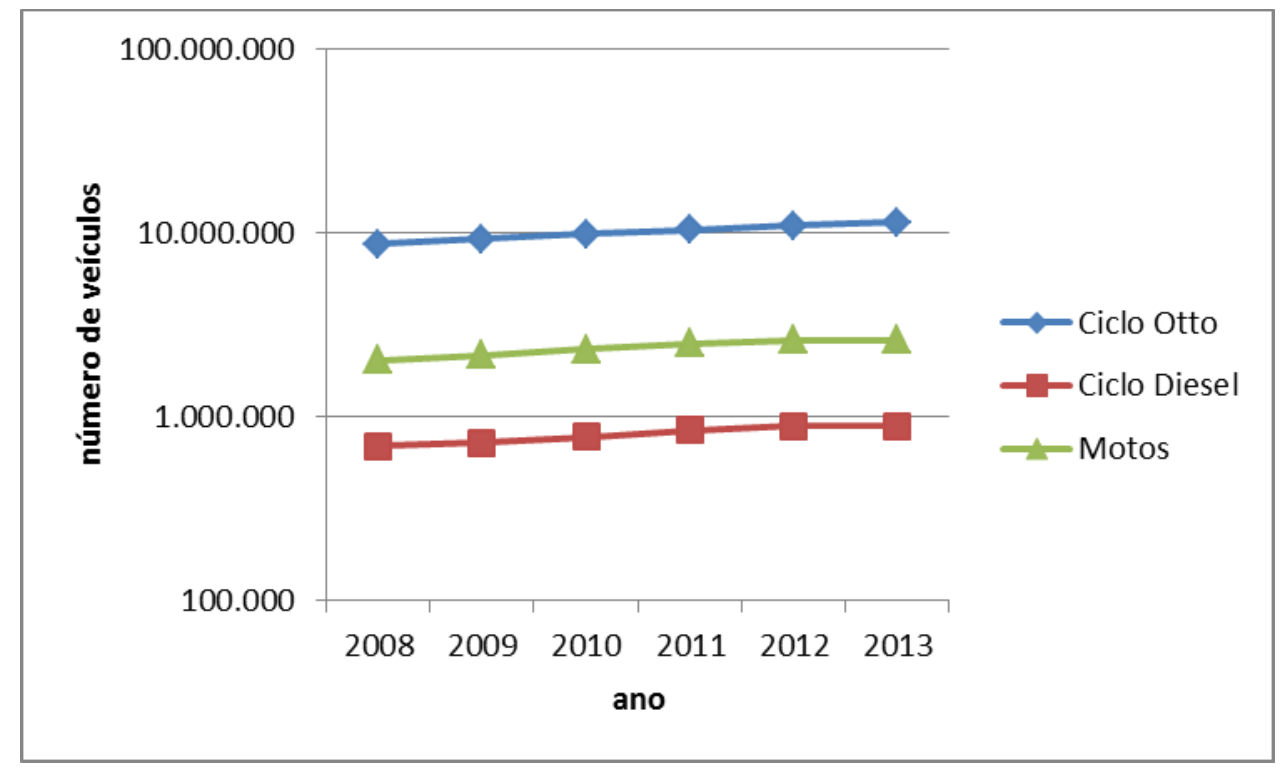




\section{CONSUMO DE COMBUSTÍVEL}

A intensidade de uso de referência é uma das variáveis da equação 1 e deve ser ajustada pelo total de combustível consumido de Gasolina C, Etanol Hidratado e Óleo Diesel observado no Estado de São Paulo.

As emissões veiculares variam também em função da frota circulante e dos fatores de emissão dos veículos por ano de fabricação e poluente, sendo que estes últimos podem considerar a deterioração do veículo decorrente da quilometragem anual acumulada, disponível somente para os veículos leves.

Para o cálculo das estimativas das emissões veiculares, foram utilizados os dados de consumo rodoviário de combustíveis fornecidos pela ANP (Agência Nacional do Petróleo, Gás Natural e Biocombustíveis) [7] e indicados na figura 2.

Figura 2. Consumo de combustíveis de uso rodoviário no Estado de São Paulo

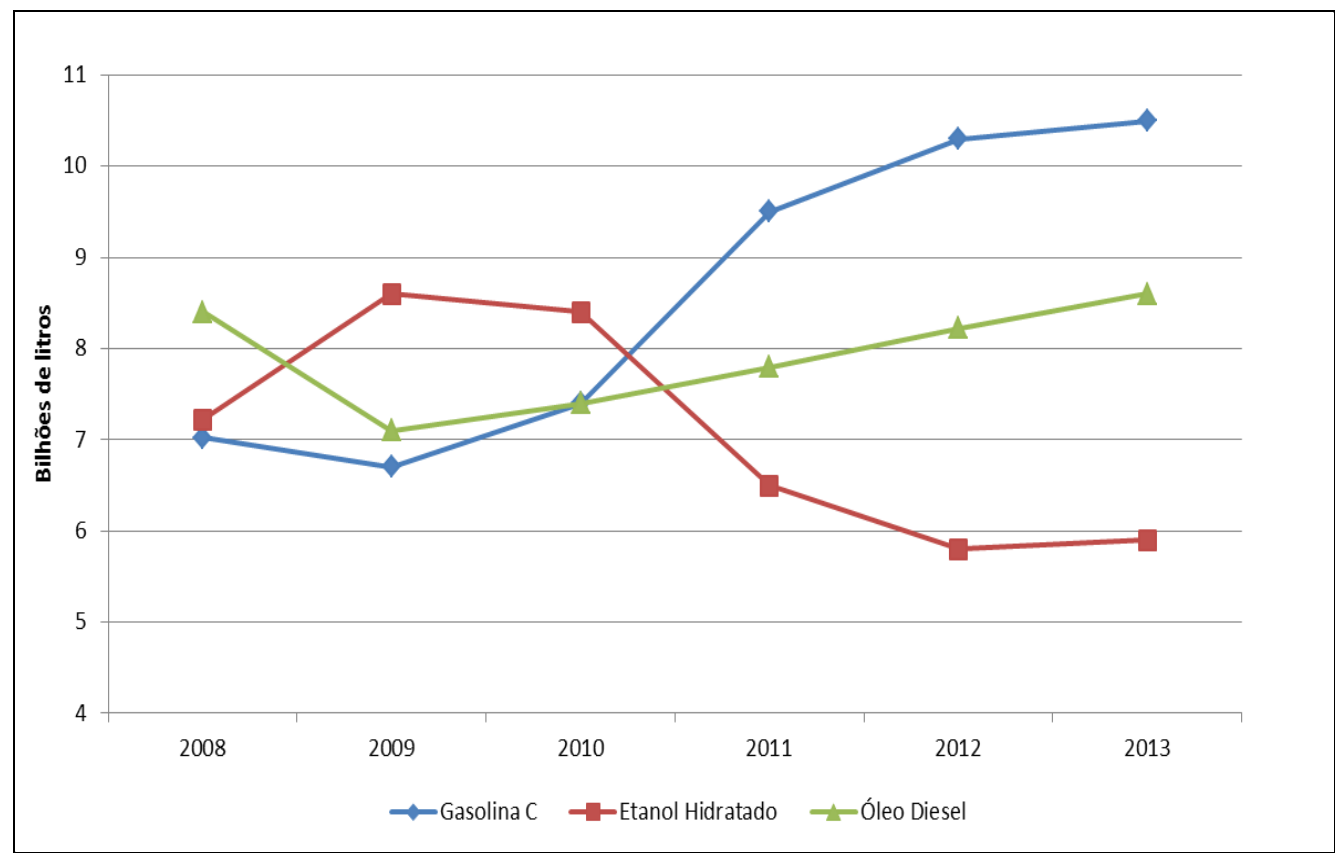

Fonte: Adaptado ANP

\section{ANÁLISE DOS RESULTADOS}

A figura 3 indica a evolução do total das emissões de CO no Estado de São Paulo, em toneladas, de 2008 a 2013. Os veículos automotores do ciclo Otto são responsáveis pela maior parcela das emissões de $\mathrm{CO}$ e apresentaram uma redução de $35 \%$ nas emissões. As motocicletas apresentaram a redução de $19 \%$ e os veículos do ciclo Diesel tiveram o aumento de 33\% na emissão de monóxido de carbono nesse período. 
Figura 3. Evolução do Total das emissões de monóxido de carbono, em toneladas, no Estado de São Paulo de 2008 a 2013

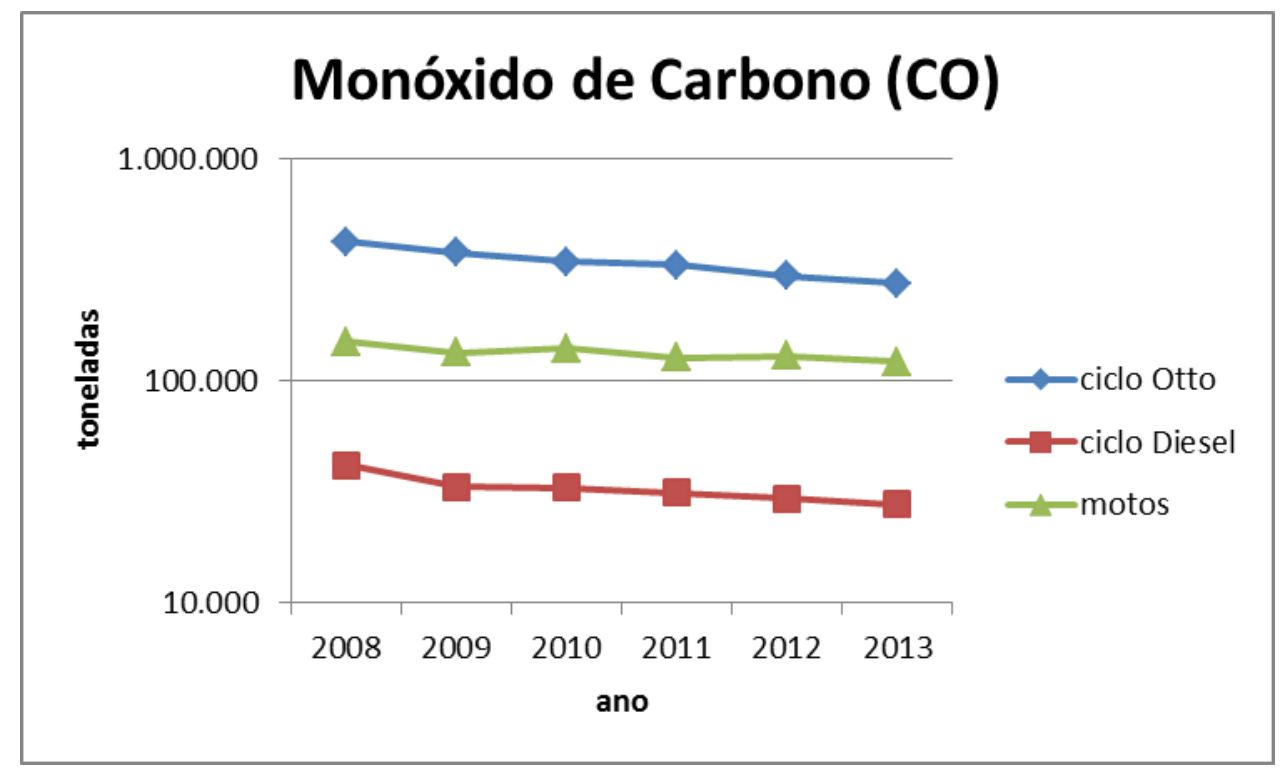

A figura 4 mostra a evolução das emissões de hidrocarbonetos não-metano (NMHC), incluindo as emissões evaporativas para automóveis e comerciais leves do ciclo Otto. Houve redução de $35 \%$ nas emissões de NMHC do ciclo Otto e a redução de $48 \%$ nas emissões de NMHC dos veículos do ciclo Diesel. As motocicletas indicaram a redução de $11 \%$ em suas emissões.

Figura 4. Evolução do Total das emissões de hidrocarbonetos não-metano em toneladas, no Estado de São Paulo de 2008 a 2013

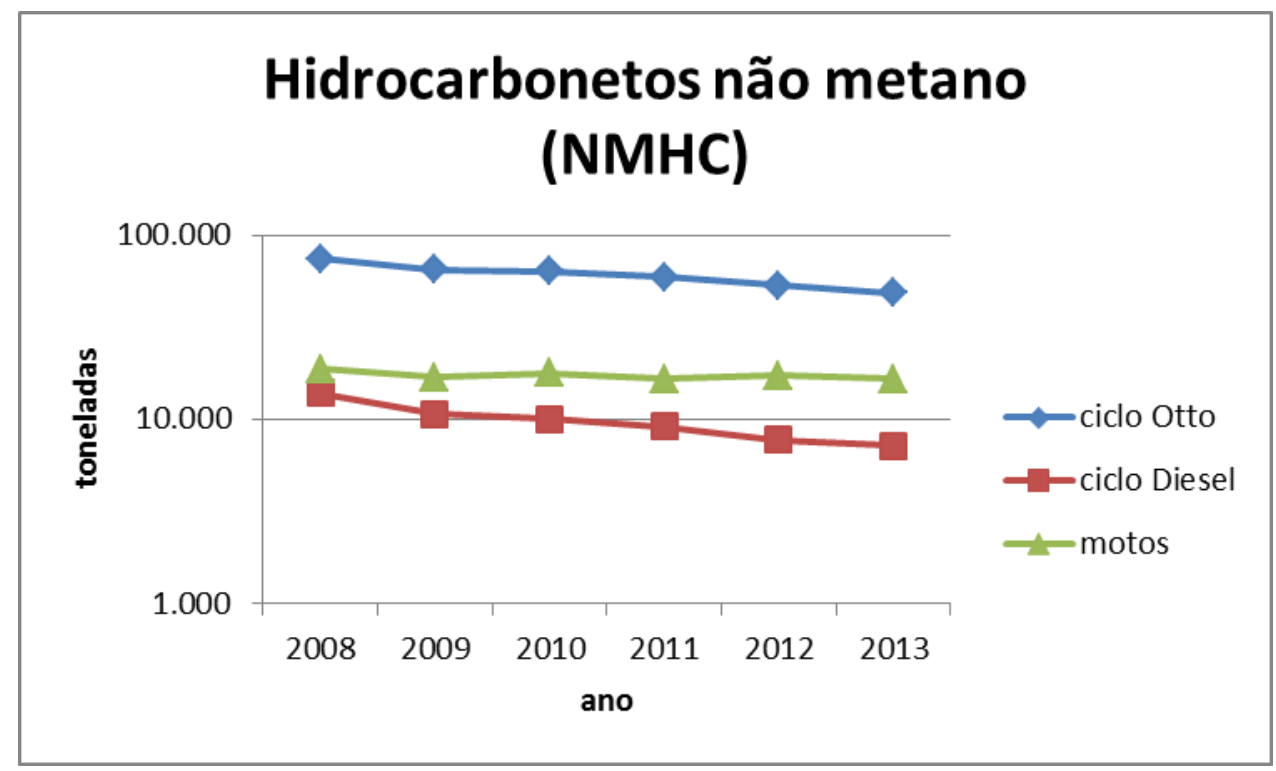

Como indica a figura 5, os veículos do ciclo Diesel são os maiores responsáveis pelas emissões de $\mathrm{NO}_{x}$, com a redução de $34 \%$ em suas emissões. Para os veículos do ciclo Otto, houve a redução de 29\% nas emissões, de 2008 a 2013. As motocicletas apresentaram o aumento de $32 \%$ das emissões de $\mathrm{NO}_{x}$. 
Figura 5. Evolução do Total das emissões de óxidos de nitrogênio em toneladas, no Estado de São Paulo de 2008 a 2013

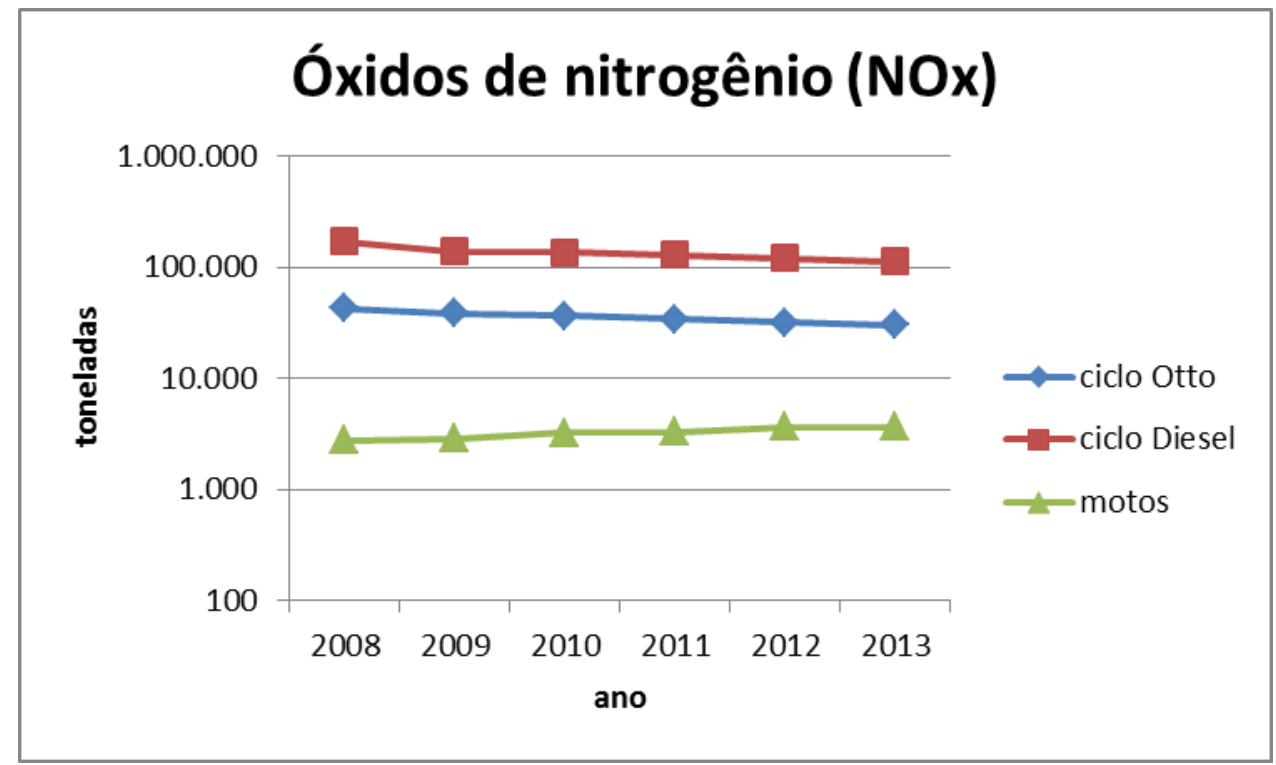

A figura 6 aponta que os veículos do ciclo Diesel também são os maiores responsáveis pelas emissões de material particulado no Estado, mas pode-se observar a redução de $52 \%$ nas emissões. Para os veículos do ciclo Otto, houve o aumento de $31 \%$, de 2008 a 2013 . As motocicletas apresentaram um aumento de $50 \%$ das suas emissões no período.

Figura 6. Evolução do Total das emissões de material particulado, em toneladas, no Estado de São Paulo de 2008 a 2013

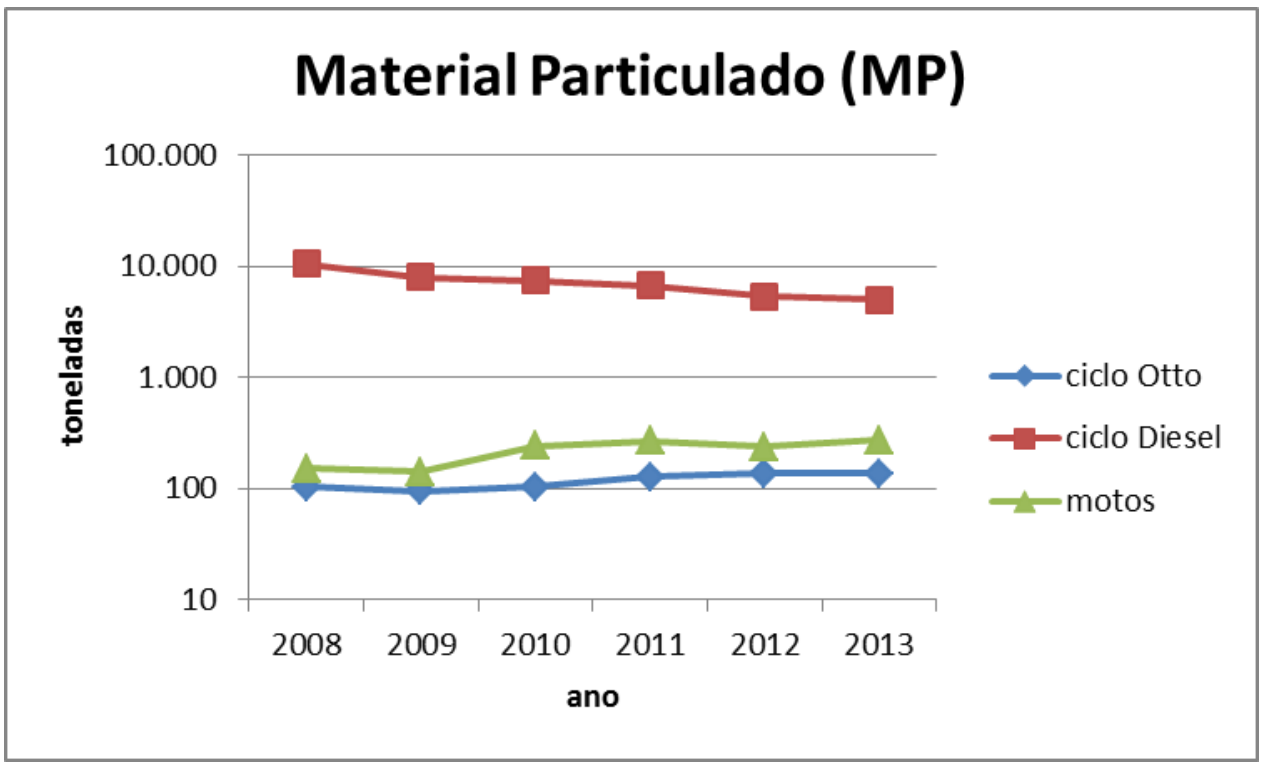


A figura 7 ilustra as emissões totais de $\mathrm{SO}_{2}$ dos veículos do ciclo Diesel, Otto e das motocicletas. Para o ciclo Diesel, observamos a redução $23 \%$ nas emissões de $\mathrm{SO}_{2}$. Para o ciclo Otto houve aumento de 48\% nas emissões, de 2008 a 2013. As motocicletas apresentaram aumento de $56 \%$ das emissões neste período. Deve-se ressaltar que as emissões de $\mathrm{SO}_{2}$ foram obtidas pela abordagem "top-down", que estão diretamente correlacionadas com o enxofre contido nos combustíveis fósseis.

Figura 7. Evolução do total das emissões de dióxido de enxofre em toneladas, no Estado de São Paulo de 2008 a 2013

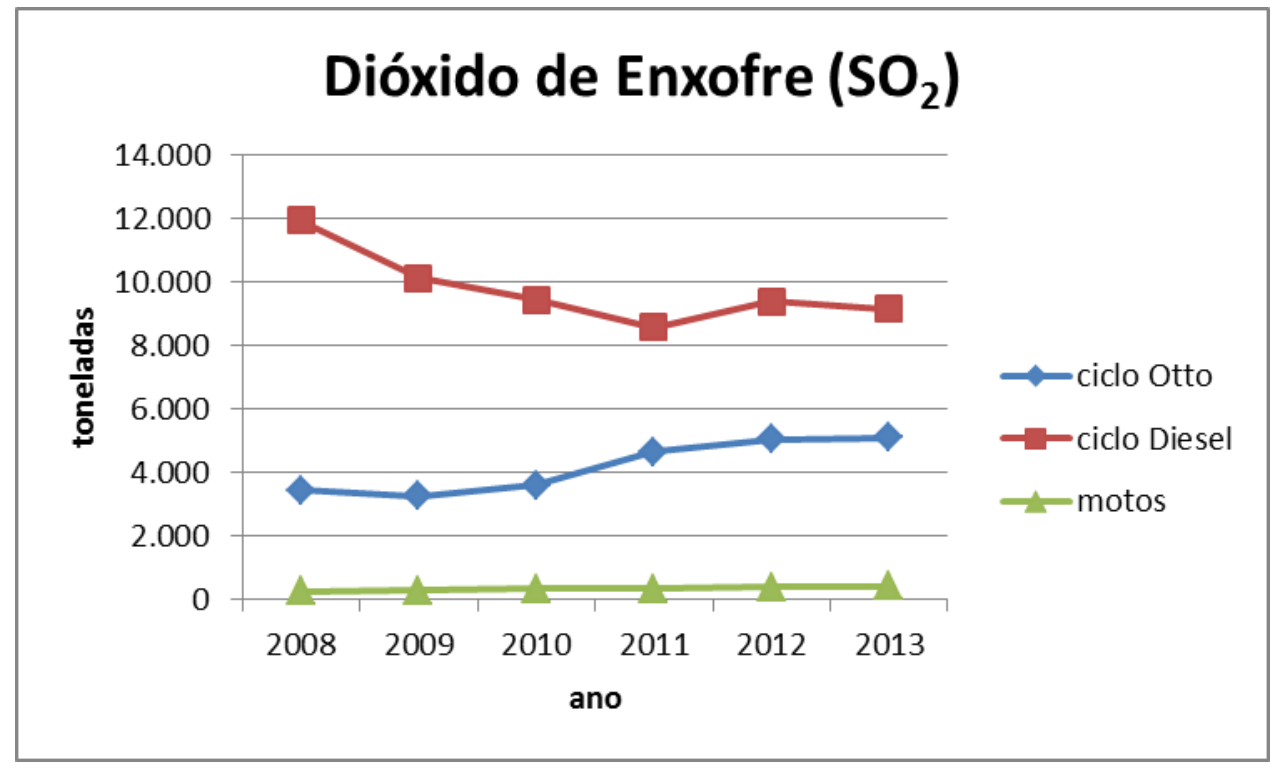

As emissões de aldeídos totais no Estado de São Paulo estão indicadas na figura 8, somente para veículos do ciclo Otto. Houve a redução de $41 \%$ nas emissões dos aldeídos totais de 2008 a 2013.

Figura 8. Evolução das emissões de aldeídos totais, em toneladas, no Estado de São Paulo de 2008 a 2013

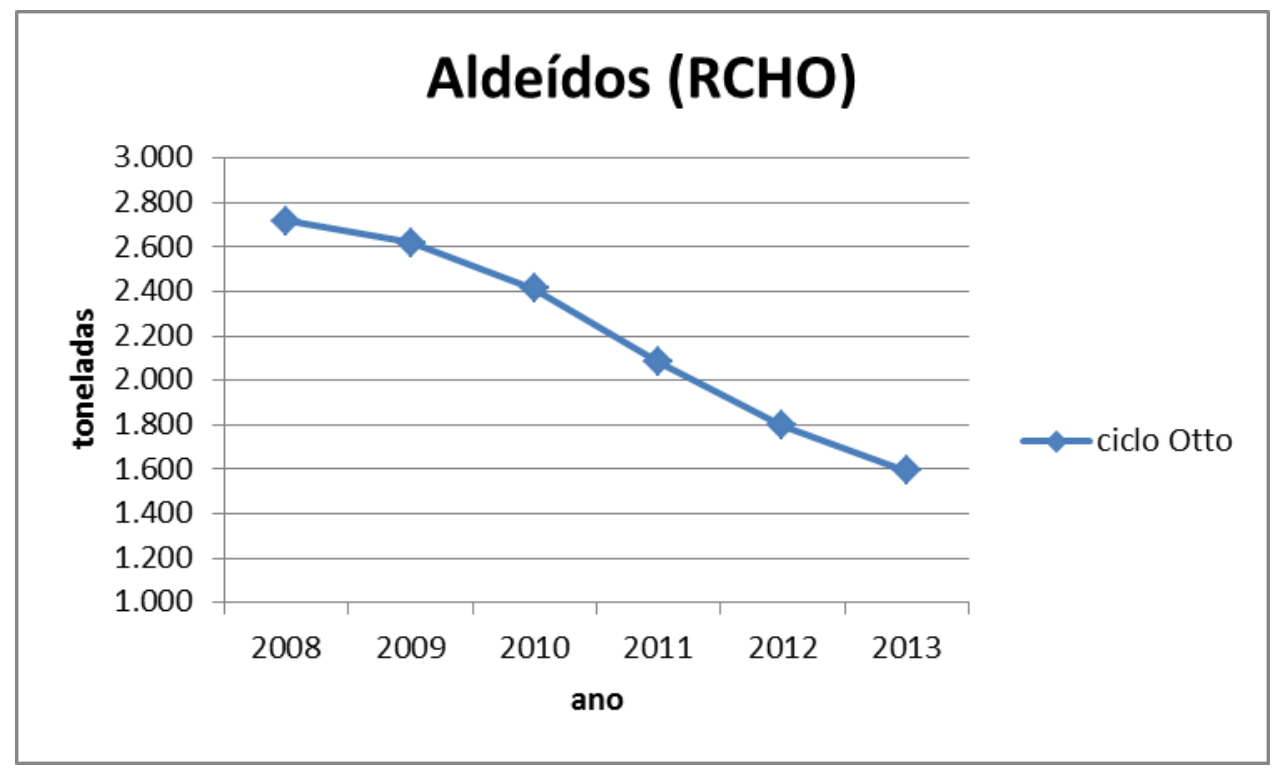


As emissões de $\mathrm{CH}_{4}$ para o Estado de São Paulo são apresentadas na figura 9. Para os veículos do ciclo Otto, a abordagem usada para o cálculo das emissões foi a "bottom-up". Para os veículos do ciclo Diesel e motocicletas, a abordagem foi a "topdown". Foram utilizados os fatores de emissão recomendados pelo IPCC. Houve a redução de $21 \%$ nas emissões totais de $\mathrm{CH}_{4}$ para os veículos do ciclo Otto e a redução de $2 \%$ para o ciclo Diesel. As motocicletas tiveram a diminuição de 15\% nas emissões de $\mathrm{CH}_{4}$ no Estado de São Paulo, de 2008 a 2013.

Figura 9. Evolução do total das emissões de metano em toneladas, no Estado de São Paulo de 2008 a 2013

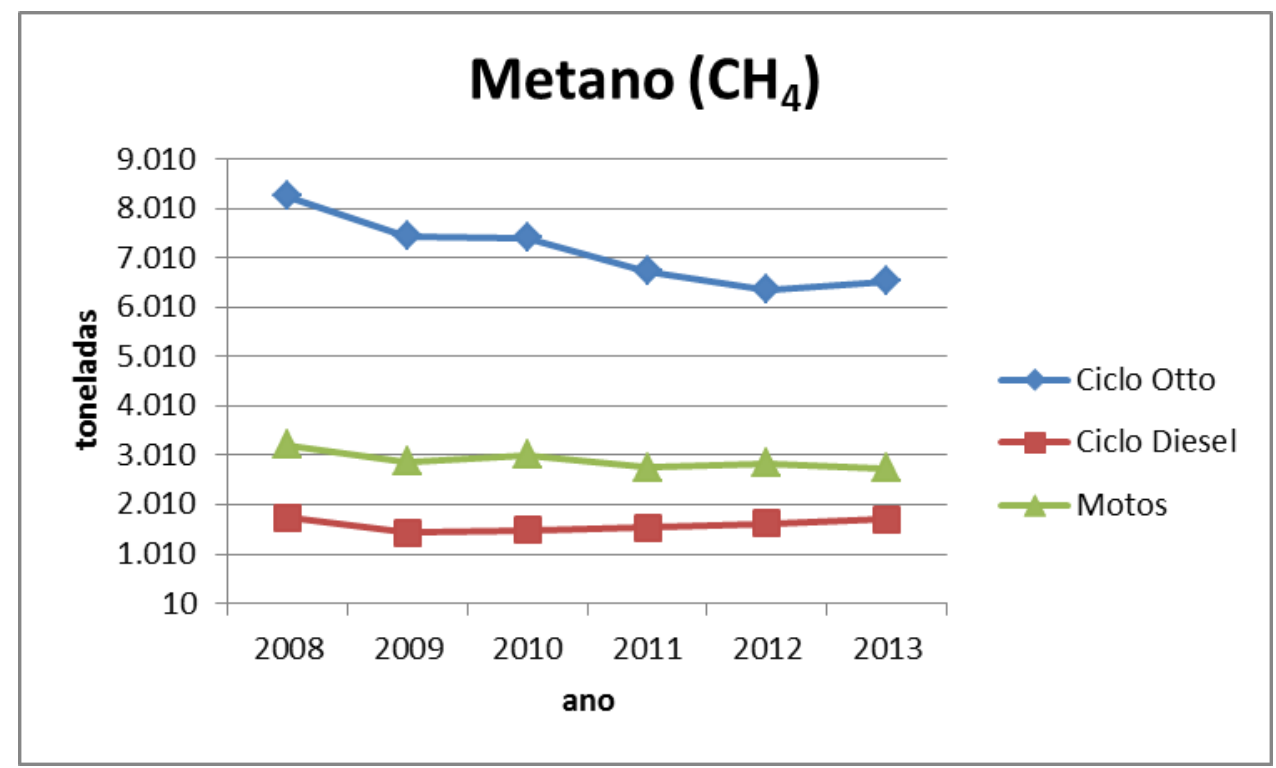

As emissões totais de $\mathrm{N}_{2} \mathrm{O}$ no Estado de São Paulo aumentaram $35 \%$ de 2008 a 2013, de acordo com a figura 10, para os veículos do ciclo Otto. Houve também um aumento de $2 \%$ para os veículos do ciclo Diesel e $45 \%$ para as motocicletas.

Figura 10. Evolução do total das emissões de óxido nitroso, em toneladas, no Estado de São Paulo de 2008 a 2013

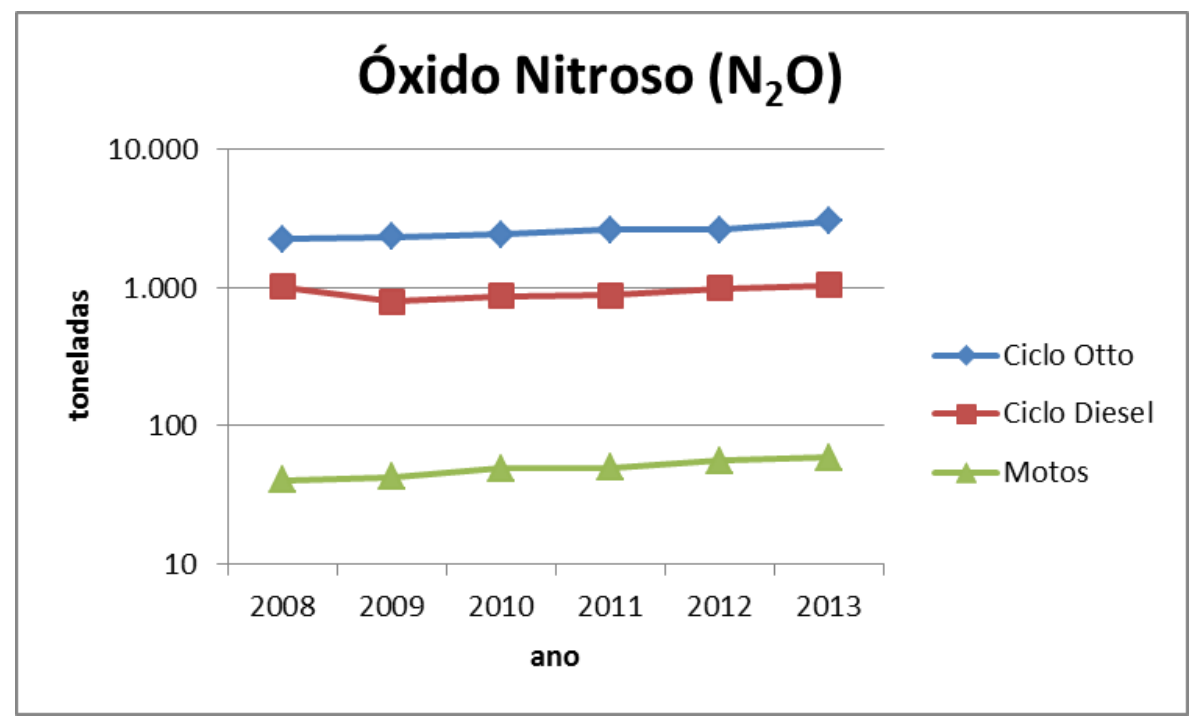


As emissões de $\mathrm{CO}_{2 \mathrm{eq}}$ foram obtidas utilizando o conceito de Potencial de Aquecimento Global (GWP), para os gases $\mathrm{CH}_{4}, \mathrm{~N}_{2} \mathrm{O}$ e $\mathrm{CO}_{2}$ e para um horizonte de 100 anos [8]. Houve aumento de $20 \%$ nas emissões de $\mathrm{CO}_{2 \text { eq }}$ no Estado de São Paulo, de 2008 a 2013, como mostrado na figura 11. Essa evolução é motivada pelo aumento da frota circulante, pelo aumento no consumo de combustível e principalmente pela redução do consumo de etanol hidratado, substituído pelo consumo de gasolina $\mathrm{C}$ nos veículos flex-fuel.

Figura 11. Evolução do total das emissões de dióxido de carbono equivalente, em toneladas, no Estado de São Paulo de 2008 a 2013

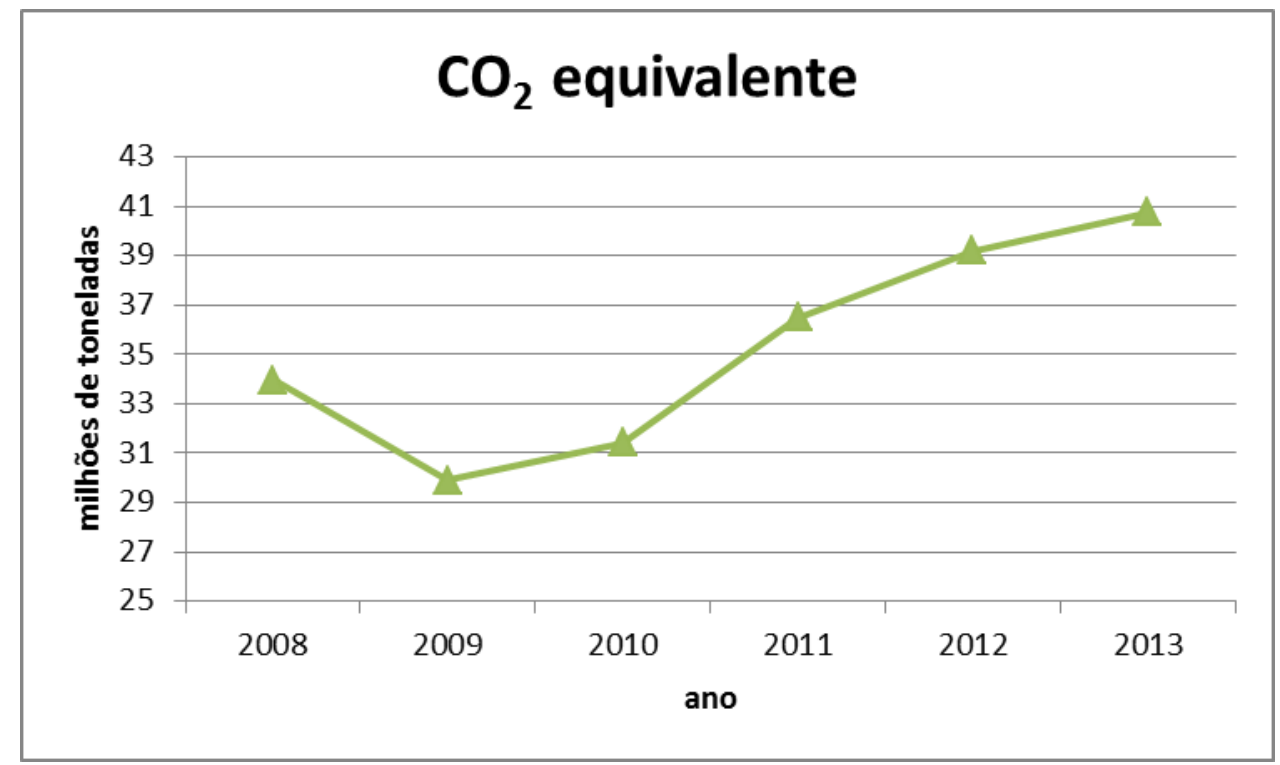

\section{CONCLUSÃO}

As estimativas de emissões veiculares dos seguintes poluentes: CO, NMHC, MP, $\mathrm{SO}_{2}, \mathrm{NO}_{\mathrm{x}}$ e aldeídos totais foram calculadas utilizando os novos valores de intensidade de uso de referência publicados pela CETESB em "Curvas de intensidade de uso por tipo de veículo automotor da frota da cidade de São Paulo" [5].

Comparativamente aos dados publicados no "Relatório de Emissões Veiculares no Estado de São Paulo", CETESB (2013) [9], com o ano base de 2012, pode-se observar que ocorreu o aumento de $37 \%$ nas emissões veiculares totais de monóxido de carbono (CO), o aumento de 32\% nas emissões totais de hidrocarbonetos não metano (NMHC), um aumento de apenas $1 \%$ nas emissões de óxidos de nitrogênio $\left(\mathrm{NO}_{\mathrm{x}}\right)$, o aumento de $7 \%$ nas emissões de material particulado (MP) e o aumento de $24 \%$ nas emissões de aldeídos (RCHO).

Os resultados das estimativas das emissões veiculares no Estado de São Paulo confirmam que os veículos do ciclo Otto, seguidos pelas motos, têm maior influência 
nas emissões de $\mathrm{CO}$ e $\mathrm{NMHC}$, devido às características do motor e do número de veículos presentes na frota circulante do Estado de São Paulo.

Os veículos do ciclo Diesel apresentam maior influência nas emissões de $\mathrm{NO}_{\mathrm{x}}$. No segmento Otto existe a tendência de queda nas emissões. O impacto da introdução dos veículos da Fase P7 do PROCONVE ainda não foi observado nas estimativas emissões veiculares, principalmente de $\mathrm{NO}_{x}$ e Material Particulado.

Para o poluente MP também o segmento Diesel se mostra mais impactante e a tendência de queda se dará da mesma forma que para o $\mathrm{NO}_{\mathrm{x}}$, com a renovação gradual da frota.

Os veículos Diesel ainda são os maiores emissores de $\mathrm{SO}_{2}$, mas seguidos de perto pelos veículos Otto. Como a emissão desse poluente está diretamente ligada ao teor de enxofre nos combustíveis, os processos de redução do teor de enxofre em curso é que levarão à redução das emissões, tanto para o Diesel quanto para a gasolina.

As emissões de aldeídos totais foram determinadas apenas para os veículos do ciclo Otto, pois ainda não há controle estabelecido para os veículos Diesel. A queda das emissões deste poluente pode ser atribuída à redução do uso de etanol hidratado neste período.

De modo geral, as motocicletas apresentaram um aumento nas emissões de poluentes, devido ao crescimento da frota.

O aumento das emissões de dióxido de carbono equivalente $\left(\mathrm{CO}_{2 e q}\right)$ pode ser atribuído ao aumento do consumo de combustíveis fósseis (Gasolina C e Diesel) de 2008 a 2013.

\section{REFERÊNCIAS}

[1] Ministério do Meio Ambiente. Inventário Nacional de Emissões Atmosféricas por Veículos Automotores Rodoviários - Relatório Final, Brasília, 2011.

[2] Associação Nacional dos Fabricantes de Veículos Automotores - ANFAVEA. Anuário da Indústria Automobilística Brasileira. Edição 2012. Disponível em <http:\I www.anfavea.com.brlanuario.html> Acesso em 25/02/2014.

[3] Associação Brasileira dos Fabricantes de Motocicletas, Ciclomotores, Motonetas, Bicicletas e Similares - ABRACICLO. Anuário da Indústria Brasileira de Motociclos 2012. Disponível em <http:॥ www.abraciclo.com.br> Acesso em 10/04/2014.

[4] Ministério da Ciência e Tecnologia. Primeiro Inventário Brasileiro de Emissões Antrópicas de Gases de Efeito Estufa. Relatório de Referência: Emissões de Gases de Efeito Estufa no Setor Energético por Fontes Móveis, 2006.

[5] Companhia Ambiental do Estado de São Paulo - CETESB. Curvas de intensidade de uso por tipo de veículo automotor da frota da cidade de São Paulo, São Paulo, 2014. 
[6] IPCC. 2006 IPCC Guidelines for National Greenhouse Gas Inventories. Prepared by the National Greenhouse Gas Inventories Programme, Eggleston H.S., Buendia L., Miwa K., Ngara T. and Tanabe K. (eds). Published:GES, Japan, 2006.

[7] Agência Nacional do Petróleo, Gás Natural e Biocombustíveis - ANP, Dados Estatísticos. Disponível em <http:॥ www.anp.gov.br> Acesso em 10/04/2014.

[8] Companhia Ambiental do Estado de São Paulo - CETESB. 1ํ. Inventário de emissões antrópicas de gases de efeito estufa diretos e indiretos do Estado de São Paulo - Comunicação Estadual, São Paulo, 2011.

[9] Companhia Ambiental do Estado de São Paulo - CETESB. Relatório de Emissões Veiculares no Estado de São Paulo, São Paulo, 2012. 